\title{
APLICAÇÃO DO PRINCÍPIO DO MELHOR INTERESSE DA CRIANÇA PELO SUPERIOR TRIBUNAL DE JUSTIÇA DE 2001 A 2018
}

\author{
THE APPLICATION OF THE PRINCIPLE OF THE BEST INTEREST OF THE CHILD BY THE \\ SUPERIOR COURT OF JUSTICE FROM 2001 TO 2018
}

Antonio Jorge Pereira Júnior ${ }^{1}$ Francisco Flávio Silva Rodrigues ${ }^{2}$

\begin{abstract}
Resumo: No presente trabalho examina-se o conjunto de 20 acórdãos do Superior Tribunal de Justiça que, no período de 2001 a fevereiro de 2018, citam o princípio do melhor interesse da criança como apoio decisório, segundo pesquisa no sítio eletrônico do Tribunal. O escopo do trabalho foi verificar se há uniformidade no critério utilizado pelos ministros quando aplicam o princípio, bem como avaliar se o uso atendeu a uma necessidade real de fundamentação jurídica ou se foi caso de simples argumento retórico de reforço, sendo, então, desnecessário. Dos 20 acórdãos examinados, somente em quatro se contatou a necessidade ou adequação do princípio. A conclusão que se chega é de que é preciso estabelecer um procedimento claro para aplicação técnica do princípio, sob risco do desgaste hermenêutico deste, que tem como efeito esvaziá-lo de sua força. A pesquisa é basicamente jurisprudencial e de análise qualitativa, uma vez examinados e avaliados os acórdãos segundo sua lógica de fundamentação.
\end{abstract}

Palavras-chave: Princípio do melhor interesse da criança. Superior Tribunal de Justiça. Convenção Internacional dos Direitos da Criança. Princípio da Prioridade Absoluta dos direitos da criança e do adolescente. Hermenêutica.

\begin{abstract}
This paper examines the set of $20 \mathrm{ju}-$ dgments of the Superior Court of Justice which, from 2001 to February 2018, cite the principle of the best interests of the child as decision support, according to a survey on the Court's website. The scope of the work was to verify if there is uniformity in the criterion used by the ministers when applying the principle, as well as to evaluate if the use met a real need of legal reasoning or if it was a simple rhetorical argument of reinforcement, and, therefore, it is unnecessary. In only four of the 20 judgments examined there was the necessity or adequacy of the principle. The conclusion is that it is necessary to establish a clear procedure for the technical application of the principle, at the risk of the hermeneutic wear of the principle, which has the effect of emptying it of its force. The research is basically jurisprudential and of qualitative analysis, once the judgments have been examined and evaluated according to their reasoning logic.
\end{abstract}

Keywords: Principle of the best interest of the child. Superior Justice Tribunal. Convention on the Rights of the Child. Principle of the Absolute Priority of the rights of children and adolescents. Hermeneutics.

\footnotetext{
Doutor, Mestre e Bacharel em Direito pela Universidade de São Paulo; Professor no Programa de Mestrado e Doutorado da Universidade de Fortaleza; Avenida Washington Soares, 1321, Edson Queiroz, 60811-905, Fortaleza, Ceará, Brasil; antoniojorge2000@gmail.com; http://orcid.org/0000-0002-0611-2869

2 Especialista em Direito de Família e Sucessões pela Universidade de Fortaleza; Bacharel e mestrando em Direito pela Universidade de Fortaleza; f_flaviorodrigues@outlook.com; http://orcid.org/0000-0001-6185-1632
} 


\section{Introdução}

Há uma tríade de princípios que são pilares da doutrina e da legislação em matéria de direitos infanto-juvenis: a prioridade absoluta, posta no art. 227 da Constituição Federal (CF) e decantada no art. 4 do Estatuto da Criança e do Adolescente (ECA); a proteção integral, constante do art. 1 do ECA, e o princípio do melhor interesse da criança, estabelecido pela Convenção Internacional dos Direitos da Criança de 1989, vigente no Brasil por força do Decreto n. 99.710, de 21 de novembro de 1990.

Cada um deles assegura direitos e impõe critérios que devem ser observados pelo Estado, pela sociedade, pela família e pelos cidadãos.

Com a finalidade de favorecer o melhor cumprimento desses princípios em sua aplicação, a pesquisa jurisprudencial ora publicada teve por escopo avaliar como o Superior Tribunal de Justiça (STJ) tem feito uso do princípio do melhor interesse da criança em suas decisões. Desse modo, o objeto de análise são as decisões vinculadas ao princípio, segundo o sitio eletrônico do Tribunal, observando-se em cada caso se houve a exposição de hipóteses que justificariam sua aplicação, bem como o contexto no qual se entendeu cabível. $\bigcirc$ parâmetro de busca são os acórdãos publicados entre 2001 e fevereiro de 2018, acessíveis segundo o sítio eletrônico.

Por antecipado, vale citar que se entende como condição adequada para aplicação técnica do princípio do melhor interesse da criança, em oposição à mera menção retórica da expressão "melhor interesse da criança", a coexistência de duas ou mais possíveis respostas legais e legítimas ao caso sob exame, sem que haja um parâmetro legal a impor a preferência por uma delas, devendo o magistrado ponderar, a partir do caso concreto e, de modo argumentativo, fundamentar sua decisão. Ou seja, quando a solução desborda da simples subsunção e há mais de uma resposta razoável e cabível. Fora desse contexto, a menção ao princípio se faria apenas como recurso retórico, por isso mesmo, de rigor, desnecessária.

A exposição da definição dos critérios para uso adequado do princípio referido, anteriormente indicado, é objeto de trabalho de mestrado na Universidade de Fortaleza acerca do princípio do melhor interesse da criança, a se concluir no segundo semestre de 2018, levado a termo por um dos autores desta análise, sob orientação do outro. Aqui, neste espaço, partilha-se parte da sondagem que serviu de base para aquele estudo, na qual se pôde identificar as variações de uso pelo mais importante Tribunal em matéria de direitos infanto-juvenis, por vezes sem utilidade efetiva, a confirmar a hipótese da ausência de critério técnico e uniforme, adequado à aplicação do princípio. Ali, no trabalho dissertativo, cada acórdão é apreciado com minudência. Aqui, recolhem-se informações suficientes para apresentar o resultado daquela análise.

Sendo diagnóstico de diversas decisões, para alcançar um resultado comparativo do conjunto decisório, avaliando-se o uso técnico de um dado princípio pelos Ministros do STJ, o presente trabalho afasta-se da forma habitual de estudo de caso, quando se privilegia a avaliação de 
um dado caso. Assim, não serão apresentados em detalhes os fatos e histórico processual de cada um dos 20 casos, senão as informações suficientes para que se saiba do tema central de cada um. A análise pormenorizada, com volume de texto respectivo, é objeto da dissertação de mestrado já referida.

O direito que se observa, nessa perspectiva, é a aplicação fundamentada do princípio do melhor interesse da criança, objeto imediato do trabalho. Logo, as decisões serão mencionadas de modo perfunctório, destacando-se o que nelas tornaria necessário, ou não, a escora no princípio do melhor interesse. A crítica, por fim, se referirá à adequação do uso do referido princípio em cada caso avaliado.

Tem-se que o estudo tem o mérito de permitir averiguar como se sedimenta a aplicação de um dos princípios nucelares em matéria de direitos da infância e juventude pela ação do Superior Tribunal de Justiça, a partir do que se torna indicador para todo o Judiciário. A partir da constatação, pode-se apontar procedimentos para uma aplicação técnica mais adequada, apta a gerar uniformidade, uma das missões do Tribunal.

\section{Descrição da metodologia}

A triagem dos acórdãos foi realizada mediante o portal do Superior Tribunal de JustiçaSTJ (http://www.stj.jus.br/SCON/), na opção "jurisprudência". O espaço permite a realização de pesquisa específica por meio de palavras-chave, com filtros que possibilitam a delimitação do campo de busca, o que oportunizou a feitura da seleção apresentada, cujo intuito era identificar a presença do "princípio do melhor interesse da criança" nas decisões desse Tribunal, a fim de se averiguar se foram tecidas considerações que mostrem critérios observados quando de sua aplicação, ou se apenas se mencionou de modo retórico ou reforçador, sem necessidade jurídica específica.

Tencionando chegar às decisões que, de forma expressa, apresentam o melhor interesse da criança como princípio, a pesquisa partiu de termos mais amplos, até chegar ao mais específico. No campo "busca livre", inicialmente usou-se a expressão "melhor interesse", surgindo um total de 128 acórdãos. Posteriormente, utilizou-se a expressão "melhor interesse da criança", com um total de 57 acórdãos. Por último, fez-se uso da expressão "princípio do melhor interesse da criança”, com o total de 20 acórdãos. A seguir apresentam-se as tabelas das respectivas triagens, mostrando a disposição dos acórdãos, a cada ano, de acordo com a data de publicação.

Após a seleção dos casos, foi realizada a análise dos acórdãos constantes da última triagem, oportunidade em que se buscou descrever a demanda discutida em cada um deles, por meio de resumo que permita ao leitor se situar em cada um dos julgados, enfatizando-se a forma como o princípio foi apresentado e se sua utilização foi imprescindível na fundamentação do caso específico. Ainda, foram tecidos breves comentários acerca de cada decisão, pretendendo compreender as razões que levaram os Ministros a utilizarem o princípio, e se tal uso ocorreu de forma coerente e justificada. 
Dados quantitativos:

a) Primeira triagem: "melhor interesse" em "pesquisa livre";

Tabela 1 - Acórdãos referidos ao "melhor interesse" de 2001 a 2018

\begin{tabular}{|l|l|l|l|l|l|l|l|l|l|l|l|l|l|l|l|l|l|l|}
\hline $\mathrm{A}$ & 01 & 02 & 03 & 04 & 05 & 06 & 07 & 08 & 09 & 10 & 11 & 12 & 13 & 14 & 15 & 16 & 17 & 18 \\
\hline $\mathrm{Q}$ & 01 & 0 & 0 & 0 & 0 & 02 & 0 & 02 & 06 & 12 & 12 & 11 & 06 & 20 & 09 & 15 & 26 & 06 \\
\hline
\end{tabular}

Notas: A = Ano; $\mathrm{Q}=$ Quantidade de acórdãos. Em 2018 o levantamento abrange somente janeiro e a primeira quinzena de fevereiro.

Gráfico 1 - Acórdãos referidos ao "melhor interesse" de 2001 a 2018

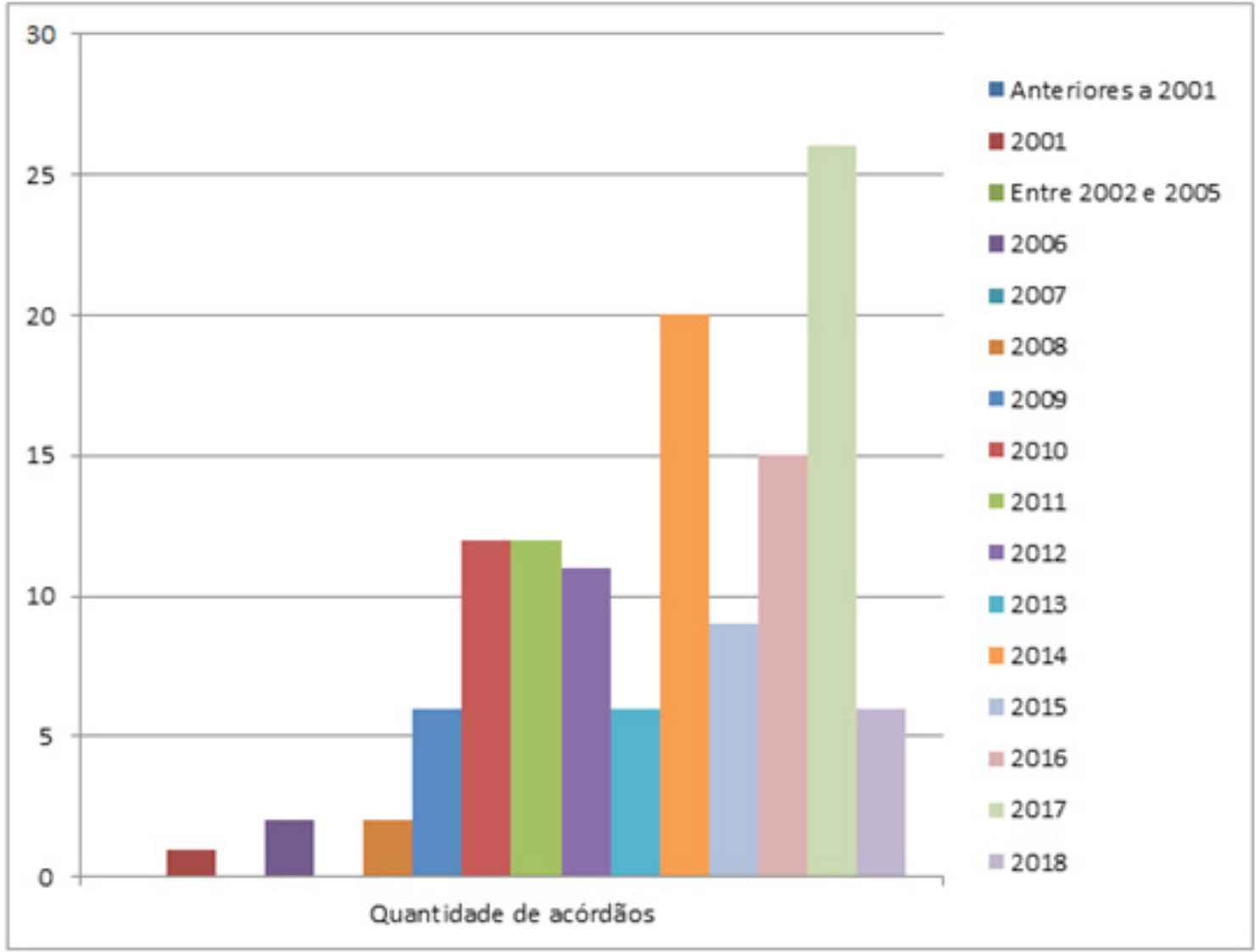

Fonte: os autores. 
b) Segunda triagem: "melhor interesse da criança" em "pesquisa livre";

Tabela 2 - Acórdãos referidos ao "melhor interesse da criança” de 2001 a 2018

\begin{tabular}{|l|l|l|l|l|l|l|l|l|l|l|l|l|l|l|l|l|l|l|}
\hline $\mathrm{A}$ & 01 & 02 & 03 & 04 & 05 & 06 & 07 & 08 & 09 & 10 & 11 & 12 & 13 & 14 & 15 & 16 & 17 & 18 \\
\hline $\mathrm{O}$ & 01 & 0 & 0 & 0 & 0 & 0 & 0 & 02 & 03 & 05 & 09 & 06 & 01 & 09 & 03 & 05 & 11 & 02 \\
\hline
\end{tabular}

Notas: A = Ano; $\mathrm{Q}=$ Quantidade de acórdãos. Em 2018 o levantamento abrange somente janeiro e a primeira quinzena de fevereiro.

Gráfico 2 - Acórdãos referidos ao "melhor interesse" de 2001 a 2018

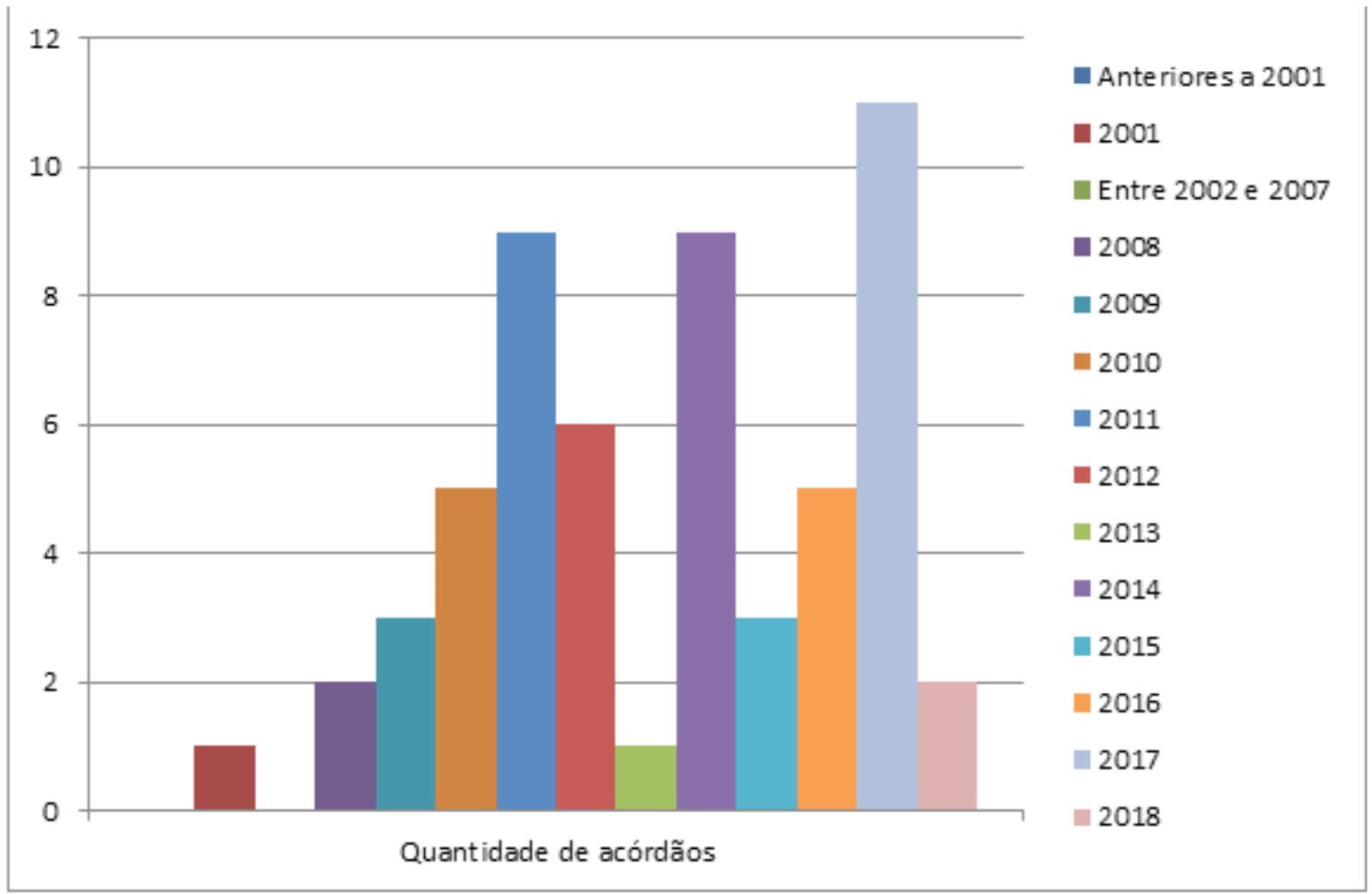

Fonte: os autores. 
c) Terceira triagem: "princípio do melhor interesse da criança" em "pesquisa livre".

Tabela 3 - Acórdãos referidos ao "princípio do melhor interesse da criança" de 2001 a 2018

\begin{tabular}{|l|l|l|l|l|l|l|l|l|l|l|l|l|l|l|l|l|l|l|}
\hline $\mathrm{A}$ & 01 & 02 & 03 & 04 & 05 & 06 & 07 & 08 & 09 & 10 & 11 & 12 & 13 & 14 & 15 & 16 & 17 & 18 \\
\hline $\mathrm{O}$ & 0 & 0 & 0 & 0 & 0 & 0 & 0 & 0 & 02 & 02 & 03 & 03 & 01 & 02 & 01 & 02 & 04 & 0 \\
\hline
\end{tabular}

Notas: A = Ano; $\mathrm{Q}=$ Quantidade de acórdãos. Em 2018 o levantamento abrange somente janeiro e a primeira quinzena de fevereiro.

Gráfico 3 - Acórdãos referidos ao "melhor interesse" de 2001 a 2018

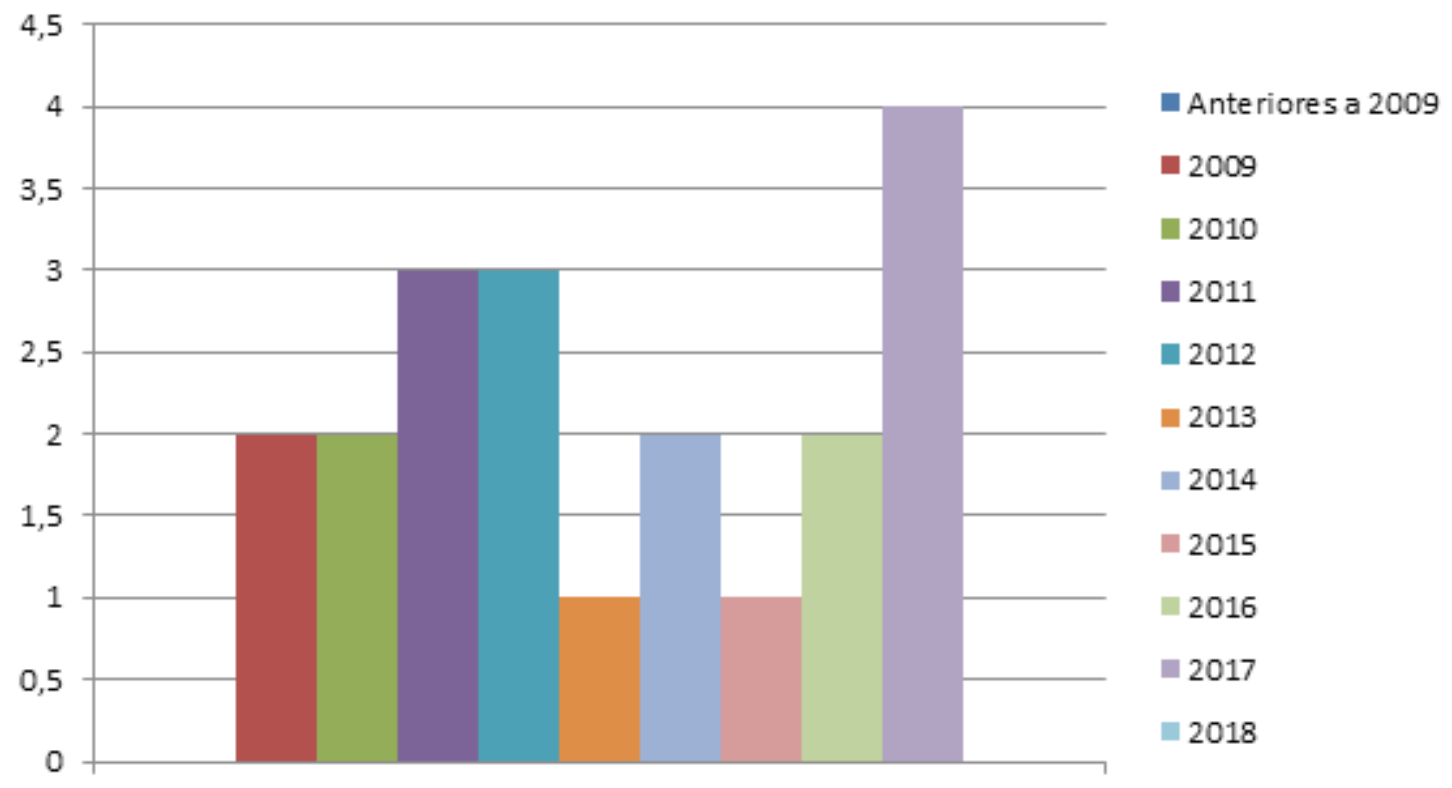

Quantidade de acórdãos

Fonte: os autores.

Conforme indicado ao começo deste artigo, escolheram-se para análise os casos em que os Ministros se referiram expressamente ao "princípio do melhor interesse da criança", como a identificar de modo preclaro o conteúdo técnico-jurídico deste. Julgou-se oportuno, todavia, trazer os critérios sucessivos de filtragem, de modo que o leitor saiba que não houve análise de acórdãos que, ainda que possam ter eventual conexão com o princípio, não foram sinalizados de modo ostensivo.

Segue-se o rol dos 20 acórdãos que mencionam o "princípio do melhor interesse da criança" de 2001 a 2018 (mês de fevereiro). A numeração segue o resultado da filtragem, em ordem do mais recente julgado encontrado (2017) ao mais antigo (2009). Ao final, nas referências, há link de acesso imediato a cada um.

1. Caso 01: AgInt no AREsp 1055042 / MS AGRAVO INTERNO NO AGRAVO EM RECURSO ESPECIAL 2017/0029670-4, de 2017.

2. Caso 02: HC 404545 / CE HABEAS CORPUS 2017/0146674-8, de 2017.

3. Caso 03: REsp 1613641 / MG RECURSO ESPECIAL 2014/0291214-0, de 2017. 
4. Caso 04: AgInt no AREsp 890218 / RJ AGRAVO INTERNO NO AGRAVO EM RECURSO ESPECIAL 2016/0077335-9

5. Caso 05: REsp 1567812 / SC RECURSO ESPECIAL 2015/0035437-7, de 2016.

6. Caso 06: REsp 1533206 / MG RECURSO ESPECIAL 2014/0345653-7, de 2016.

7. Caso 07: CC 134471 / PB CONFLITO DE COMPETENCIA 2014/0147217-1, de 2015.

8. Caso 08: REsp 1449560 / RJ RECURSO ESPECIAL 2014/0081041-3, de 2014.

9. Caso 09: HC 294729 / SP HABEAS CORPUS 2014/0114624-9, de 2014.

10. Caso 10: REsp 1293800 / MG RECURSO ESPECIAL 2011/0267867-2, de 2013.

11. Caso 11: REsp 1347228 / SC RECURSO ESPECIAL 2012/0096557-1, de 2012.

12. Caso 12: CC 119318 / DF CONFLITO DE COMPETÊNCIA 2011/0240460-3, de 2012.

13. Caso 13: REsp 1207185 / MG RECURSO ESPECIAL 2010/0149110-0, de 2011.

14. Caso 14: REsp 1215551 / RJ RECURSO ESPECIAL 2010/0189908-5, de 2012.

15. Caso 15: REsp 1199940 / RJ RECURSO ESPECIAL 2010/0117974-5, de 2011.

16. Caso 16: CC 111130 / SC CONFLITO DE COMPETÊNCIA 2010/0050164-8, de 2011.

17. Caso 17: REsp 1106637 / SP RECURSO ESPECIAL 2008/0260892-8, de 2010.

18. Caso 18: MC 16357 / DF MEDIDA CAUTELAR 2009/0238787-0, de 2010.

19. Caso 19: REsp 1058689 / RJ RECURSO ESPECIAL 2008/0107988-3, de 2009.

20. Caso 20: REsp 964836 / BA RECURSO ESPECIAL 2007/0151058-1, de 2009.

A análise realizada serviu para mostrar possíveis hipóteses de aplicação que nortearam o uso do princípio do melhor interesse da criança pelo STJ, em demandas que tratam de destituição do poder familiar, adoção, reconhecimento de filiação socioafetiva, alimentos, entre outras que estejam a discutir o interesse de crianças e adolescentes.

Conforme se observou, nas decisões posteriores ao reconhecimento do oportuna e fraziam expressamenterecisõeso as variaiu de fonte de fundamentar a decis "princípio do melhor interesse da criança", expresso na Convenção sobre os Direitos da Criança de 1989, vigente no Brasil desde 21 de novembro 1990, não há um procedimento uniforme a guiar os ministros do STJ quando da aplicação do princípio investigado.

Após a triagem realizada, pôde-se chegar ao resultado de 20 acórdãos que faziam expressa menção ao "princípio do melhor interesse da criança", sendo diversas as hipóteses de aplicação que, em maior ou menor medida, implicaram a fundamentação das decisões com base no respectivo princípio.

\section{Análise crítica}

No conjunto dos julgados estudados, pode-se notar a presença de demandas de diversas naturezas, sendo: uma sobre destituição do poder familiar; seis tratando de adoção; uma objetivando 
o reconhecimento de paternidade socioafetiva; três analisando questões de alimentos; uma acerca de tutela de menor; uma envolvendo Cooperação Jurídica entre Estados; duas analisando pedido de busca, apreensão e restituição de infante; uma a respeito de suprimento de consentimento paterno; e uma sobre guarda.

Gráfico 4 - Demandas encontradas nos julgados estudados.

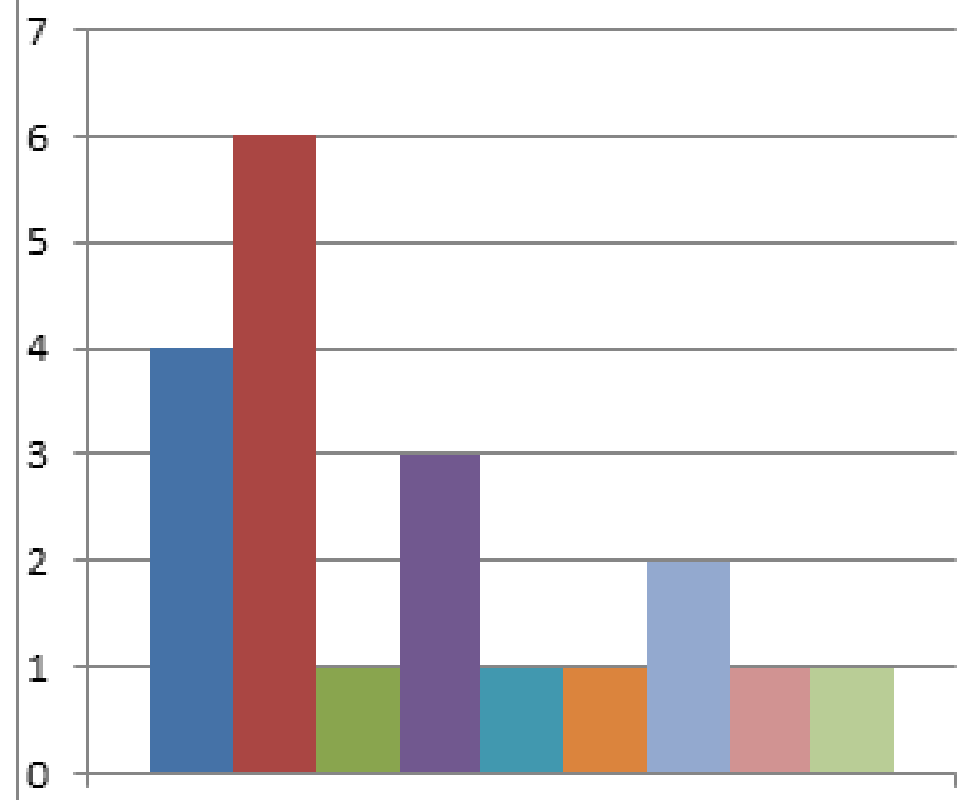

Natureza das de mandas
- Dest ituição do poder familiar

Adoção

Reconhecimento de filiação socioaetiva

- Alimentos

Tute la

Coope ração jurídica entre Estados

Busca, apreensão e restituição de menor Suprimento de consentimento paterno Guarda

Fonte: os autores.

Em alguns casos o princípio do melhor interesse foi invocado de forma totalmente descontextualizada, ao aparecer unicamente na ementa do acórdão, como no caso 01, no qual a decisão restou fundamentada unicamente na súmula 07 do STJ, que inadmite recurso especial com a simples pretensão de reexame de provas, o que mostra não ter havido discussão a ensejar a aplicação do princípio do melhor interesse da criança de modo técnico. Ainda que se fosse abordar a situação da criança no caso específico, a fim de se constatar a necessidade ou não de destituição do poder familiar (eis o tema), no Código Civil há previsão expressa a indicar os casos nos quais os pais perderão o poder familiar, que apenas ocorrerá quando a permanência junto à família for desfavorável à criança, o que está caracterizado na pretensão em análise, visto as inúmeras tentativas de reinserção do infante no seio familiar, bem como a inaptidão da genitora para cuidar do filho.

A menção unicamente na ementa do acórdão se repetiu no caso 13, no qual novamente inexistia um aprofundamento acerca do conteúdo do princípio em comento e sua consequente viabilidade na fundamentação da decisão. Todavia, em a demanda discutindo se haveria a possibilidade de adoção sem consentimento do genitor, poderia o caso ser resolvido com a disposição do art. 1.624 
do Código Civil, vigente à época, que estabelecia hipóteses nas quais é dispensado o consentimento do responsável legal do infante. Por outro lado, fez-se uso da afetividade como critério a justificar a pretensa adoção, que foi o argumento utilizado como critério decisivo no caso específico. Ou seja, o princípio do melhor interesse restou expresso sem qualquer necessidade para fundamentar a decisão.

No mesmo sentido está o caso 18, que, igualmente, apresenta o princípio do melhor interesse da criança apenas na ementa do acórdão. A demanda que objetivava o suprimento do consentimento paterno, em sede cautelar, sequer apresentava os requisitos indispensáveis ao juízo perfunctório, o que por si já afastava o possível êxito, nos termos pretendidos. Ainda, adentrando no contexto do melhor interesse da criança, a razão está em reconhecer que, devendo prevalecer a decisão mais favorável ao infante, que se compreendeu ser sua permanência no Brasil, ao se preservar o direito prioritário à convivência familiar e comunitária, conforme expresso no art. 227 da Constituição, não havia, para tanto, necessidade de invocação do princípio do melhor interesse da criança. O caso 19 versa sobre ação de alimentos, e o STJ entendeu que deveria ser anulada a primeira decisão judicial pelo valor irrisório que teria sido fixado, em razão do melhor interesse da criança, que aparece uma vez no acórdão, tal qual na ementa, sem qualquer desenvolvimento. De rigor, é desnecessária a menção. Bastaria mencionar a necessidade efetiva da criança, com direito prioritário, dentro da referência possibilidade-necessidade que pauta os alimentos.

O caso 20 apresenta situação semelhante, com a presença do princípio do melhor interesse da criança tão somente na ementa do julgado. Nesse caso, a controvérsia ocorreu em saber qual dos pais se encontrava em melhores condições de exercer a guarda, e, embora fazendo uso dos dispositivos do ECA que regulamentavam o instituto, também se fez uso do relatório social e do depoimento dos filhos, que serviram para fundamentar o voto, sem que houvesse qualquer abordagem acerca do princípio em comento.

Assim, como primeira conclusão, conforme se observa, dos 20 acórdãos estudados, pode-se dizer que cinco deles trazem o princípio basicamente na ementa do julgado, sem desenvolvimento no decorrer dos votos. Restam outros 15 a serem comentados.

Ainda diante do resultado alcançado após a pesquisa empírica, observa-se grande incidência do uso do princípio do melhor interesse da criança em questões tratando de adoção. Em um dos casos dessa natureza (caso 02), embora não sendo tecidas maiores considerações sobre o mencionado princípio, este serviu pra afastar um conflito existente entre normas aplicáveis ao caso, em que por um lado há a exigência legal de prévia inscrição, daqueles que pretendem adotar, no Cadastro Nacional de Adoção, estando expressas as exceções a essa regra, enquanto, por outro lado, o art. 98 do ECA dispõe que a medida de abrigamento deve ocorrer apenas em último caso, quando os direitos dos infantes forem ameaçados ou violados. Portanto, o princípio do melhor interesse da criança serviu a mostrar que o interesse prioritário dos filhos restou melhor atendido quando se decidiu que deveriam permanecer junto à família com a qual conviviam e de quem recebiam cuidados, situação que não poderia ser afastada por conta de uma previsão legal que exige a prévia inscrição no cadastro de adotantes. 
Em outro caso de adoção, o caso 05, o princípio do melhor interesse da criança serviu a conjugar as normas aos fatos do caso específico, de modo que seu uso fundamentou o afastamento dos vícios formais do procedimento, em prol do prioritário interesse das crianças, atendido pela decisão que sobrepõe o vínculo afetivo existente entre as crianças e a família com a qual convivem há cinco anos.

O caso 09 também discute a necessidade de observância do cadastro, havendo, novamente, um afastamento da exigência legal, possibilitando-se a prevalência da relação afetiva existente no núcleo familiar, sendo mais favorável ao infante a decisão pela permanência junto ao casal não inscrito no cadastro, mas com o qual a criança já estabeleceu vínculos.

No caso 11, novamente tratando de adoção, percebe-se a tendência dos Ministros do STJ em reconhecer a socioafetividade como hipótese caracterizadora de situação que merece preferência, tendo-se como necessário fundamentar a decisão no princípio do melhor interesse, em razão de haver dispositivo legal em sentido contrário, também no interesse, genérico e abstrato, da criança. $\mathrm{Na}$ demanda, em primeira e segunda instância, entendeu-se que o curto lapso temporal de permanência da criança junto à família postulante não serviria a configurar um vínculo afetivo suficiente para afastar a ordem cronológica do cadastro de adoção (a lei exige esse tempo), de forma que mesmo habilitado, o casal não poderia permanecer com a criança. Já quando da análise pelo STJ, admitiu-se a relação socioafetiva existente entre a criança e os postulantes, hipótese que mais uma vez implicou o afastamento da exigência formal.

Para ilustrar nesse mesmo sentido, vale dizer que, embora algumas decisões tenham utilizado o princípio, de forma expressa, tão somente na ementa pôde-se perceber, como no caso 13, que trata de adoção, que a hipótese a caracterizar o melhor interesse da criança foi a existência de vínculo socioafetivo com o postulante, que teria servido a afastar a necessidade de prévia destituição do poder familiar do pai biológico, bastando a anuência da genitora, e dispensando-se a concordância paterna. O caso 17 guarda similitude com este, e a menção ao princípio do melhor interesse tem conotação retórica, sendo desnecessária para fundamentar a decisão.

Depreende-se que, quando das questões envolvendo adoção, o principal argumento, a embasar as decisões, em sede do STJ, toma por base a socioafetividade existente nas relações familiares, critério que tem servido para afastar exigências formais, como a observância às regras do cadastro de adoção. Para fazer essa opção, em detrimento de outro comando legal, os ministros relatores faziam uso do princípio do melhor interesse, que tem sobretudo uma função procedimental: autorizar decisão em aparente conflito com norma expressa. A fundamentação deve trazer, então, a justificativa que harmoniza a disposição judicial com o sistema, resolvendo-se, em plano mais elevado, a ilusória contradição.

Ainda, conforme os casos 12 e 16, pode-se compreender que em questões envolvendo conflito de competência, prima-se pelo juízo que está mais próximo ao infante e que poderá ter acesso direto a este, o principal e preferencial carecedor de proteção jurídica. No mesmo sentido foi a decisão que consta do caso 07, na qual, embora inexistindo uma clara contextualização acerca da aplicação do princípio, 
este foi usado para afastar a perpetuatio jurisdictionis, novamente sobrelevando o juízo que possui maiores possibilidades de estar em contato com o infante, o que não implica o não aproveitamento dos atos processuais anteriores. Nesses casos, ainda que se pudesse invocar o princípio do melhor interesse, entende-se que seria suficiente o princípio da prioridade absoluta, não mencionado, pois serviria ele para justificar a preferência pelo interesse da criança, em oposição ao interesse de adulto.

A socioafetividade como pressuposto para a referência ao "princípio do melhor interesse da criança" não está presente apenas nas questões relacionadas à adoção, mas também em matérias como a do caso 03, em que o postulante pretendia anular o registro civil de sua filha, alegando não ser o pai biológico, restando entendido, em sede do STJ, que, além de não haver vício de consentimento a justificar a anulação, restaria comprovada existência da paternidade socioafetiva, fator este que contribuiu para a efetivação do interesse maior da filha.

Em outras situações, como nos casos 04,14 e 15, o princípio foi invocado desnecessariamente, quando bastaria o suporte ofertado pela codificação existente, que expressamente dispõe as hipóteses nas quais caberá a suspensão ou perda do poder família; ou seja, se no caso específico verificou-se que a conduta da genitora não condizia com o poder-dever atribuído aos pais, configurando inequívoca situação de negligência e abandono. Não seria necessária a invocação do princípio, quando há regra específica a legitimar a decisão, sem conflito com outra norma. Ou seja, não há concorrência entre "interesses da criança", legalmente tutelados, que seria requisito para recurso ao princípio do melhor ou superior interesse. Melhor e superior são termos comparativos. No caso, entre dois ou mais interesses, resguardados pela lei, do mesmo titular.

Algumas demandas evidenciam a real necessidade de invocação de um princípio, como no caso 06 , em que o princípio serviu para ponderar quais direitos prevaleceriam no caso individual, de um lado estando os direitos do filho, como vida, saúde e dignidade, quando oportunamente pleiteava alimentos, e, por outro lado, os direitos inerentes ao pai, como propriedade, liberdade e nome, de modo que os Ministros entenderam que o melhor interesse estaria atendido quando da sobreposição dos interesses do filho, sendo prioritários os direitos da criança. Todavia, de rigor, o Ministro poderia ter-se socorrido do princípio da prioridade absoluta dos direitos infanto-juvenis para o mesmo efeito, como se expôs anteriormente, pois se trata de conflito entre interesse da criança e de um adulto.

O caso 08 , do conjunto analisado, parece apresentar a invocação mais oportuna do princípio, visto que a demanda trata do pleito entre duas avós que disputam a guarda do neto, em sede de igualdade, sendo que uma reside no Brasil e outra na França, de forma que o melhor interesse é efetivado quando os Ministros ponderam diversos fatores do caso específico, como a saúde da criança, para afirmar ser adequada a sua permanência no Brasil.

O princípio foi analisado pelo Ministro relator no caso 10, e, embora ao final tenha restado uma fundamentação pautada na súmula 07 do STJ, vale ressaltar de que forma o princípio foi compreendido. Para o relator, a correta compreensão de seu conteúdo e modo de aplicação é no sentido de atribuir ao julgador o dever de analisar diversas características no caso específico, como 
os laços afetivos existentes, a comunidade na qual a criança está inserida, o lar onde vive, a escola e os laços religiosos que possui.

Percebe-se, pois, que há uma grande diversidade de contextos nos quais o princípio é referido, e, em muitos deles, o princípio tem sido usado sem apresentar coerência, e outras vezes poderia ceder lugar a princípios e regras específicos, que adequadamente fundamentariam a decisão. O uso inadequado torna-se ainda mais perceptível nos acórdãos que mencionam o princípio tão somente na ementa, o que deixa transparecer uma invocação apenas retórica.

\section{Conclusão crítica}

Pode-se colocar o seguinte quadro, de acordo com o uso técnico adequado e fundamentado e o uso desnecessário. Tem-se por "desnecessário" o uso quando se pode alcançar o mesmo resultado decisório sem apelar ao princípio.

Quadro 1 - Casos e seus usos

\begin{tabular}{|c|c|}
\hline Caso & $\begin{array}{l}\text { Uso } \\
\text { Adequado/Desnecessário }\end{array}$ \\
\hline $\begin{array}{l}\text { Caso 01: AgInt no AREsp } 1055042 \text { / MS AGRAVO INTERNO NO AGRAVO EM RECURSO } \\
\text { ESPECIAL 2017/0029670-4, de } 2017 .\end{array}$ & Uso desnecessário \\
\hline Caso 02: HC 404545 / CE HABEAS CORPUS 2017/0146674-8, de 2017. & Uso desnecessário \\
\hline Caso 03: REsp 1613641 / MG RECURSO ESPECIAL 2014/0291214-0, de 2017. & Uso desnecessário \\
\hline $\begin{array}{l}\text { Caso 04: AgInt no AREsp } 890218 \text { / RJ AGRAVO INTERNO NO AGRAVO EM RECURSO } \\
\text { ESPECIAL 2016/0077335-9 }\end{array}$ & Uso desnecessário \\
\hline Caso 05: REsp 1567812 / SC RECURSO ESPECIAL 2015/0035437-7, de 2016. & Uso adequado \\
\hline Caso 06: REsp 1533206 / MG RECURSO ESPECIAL 2014/0345653-7, de 2016. & Uso desnecessário \\
\hline Caso 07: CC 134471 / PB CONFLITO DE COMPETENCIA 2014/0147217-1, de 2015. & Uso desnecessário \\
\hline Caso 08: REsp 1449560 / RJ RECURSO ESPECIAL 2014/0081041-3, de 2014. & Uso adequado \\
\hline Caso 09: HC 294729 / SP HABEAS CORPUS 2014/0114624-9, de 2014. & Uso adequado \\
\hline Caso 10: REsp 1293800 / MG RECURSO ESPECIAL 2011/0267867-2, de 2013. & Uso desnecessário \\
\hline Caso 11: REsp 1347228 / SC RECURSO ESPECIAL 2012/0096557-1, de 2012. & Uso adequado \\
\hline Caso 12: CC 119318 / DF CONFLITO DE COMPETÊNCIA 2011/0240460-3, de 2012. & Uso desnecessário \\
\hline Caso 13: REsp 1207185 / MG RECURSO ESPECIAL 2010/0149110-0, de 2011. & Uso desnecessário \\
\hline Caso 14: REsp 1215551 / RJ RECURSO ESPECIAL 2010/0189908-5, de 2012. & Uso desnecessário \\
\hline Caso 15: REsp 1199940 / RJ RECURSO ESPECIAL 2010/0117974-5, de 2011. & Uso desnecessário \\
\hline Caso 16: CC 111130 / SC CONFLITO DE COMPETÊNCIA 2010/0050164-8, de 2011. & Uso desnecessário \\
\hline Caso 17: REsp 1106637 / SP RECURSO ESPECIAL 2008/0260892-8, de 2010 & Uso desnecessário \\
\hline Caso 18: MC 16357 / DF MEDIDA CAUTELAR 2009/0238787-0, de 2010. & Uso desnecessário \\
\hline Caso 19: REsp 1058689 / RJ RECURSO ESPECIAL 2008/0107988-3, de 2009. & Uso desnecessário \\
\hline Caso 20: REsp 964836 / BA RECURSO ESPECIAL 2007/0151058-1, de 2009. & Uso desnecessário \\
\hline
\end{tabular}

Fonte: os autores.

A análise mostra que não há uma uniformidade no concernente ao uso do princípio do melhor interesse da criança, de modo que por vezes o princípio tem sido utilizado na fundamentação 
de decisão, mas sem receber aporte teórico que o justifique, como também não há contextualização direta e adequada com o caso individual.

Em outros acórdãos, todavia, foi possível perceber a necessidade de invocação do princípio em estudo, a fim de ponderar entre as possíveis normas aplicáveis ao caso, ou mesmo para sobrelevar os direitos infanto-juvenis em face de regras processuais e de direitos inerentes aos pais ou responsáveis, para o que, de rigor, melhor seria invocar o princípio da prioridade absoluta.

Pela análise, mostra-se relevante avaliar metodologias de aplicação do princípio do melhor interesse da criança, de modo a se colaborar para que se aperfeiçoe a técnica de aplicação, evitando-se o uso retórico da expressão. Isso vale para este e outros princípios.

\section{Referências}

BRASIL. Superior Tribunal de Justiça. Agravo Interno no Agravo em Recurso Especial no 1.055.042/ MS. Relator: Ministro Marco Aurélio Bellizze. Órgão Julgador: Terceira Turma. Julgamento em 14 nov. 2017. Disponível em: <https://ww2.stj.jus.br/processo/revista/inteiroteor/? num_registro $=201700296704 \& d t \_p u b l i c a c a o=27 / 11 / 2017>$. Acesso em: 15 fev. 2018.

BRASIL. Superior Tribunal de Justiça. Agravo Interno no Agravo em Recurso Especial n ${ }^{\circ}$ 890.218/RJ. Relator: Ministro Raul Araújo. Órgão Julgador: Quarta Turma. Julgamento em 16 fev. 2017. Disponível em: <https://ww2.stj.jus.br/processo/revista/inteiroteor/?num_registro $=201600773359 \& d t \_p u b l i c a c a o=09 / 03 / 2017>$. Acesso em: 15 fev. 2018.

BRASIL. Superior Tribunal de Justiça. Conflito de Competência n 111.130/SC. Relatora: Ministra Nancy Andrighi. Órgão Julgador: Terceira Turma. Julgamento em 08 set. 2010. Disponível em: $<$ https://ww2.stj.jus.br/processo/revista/inteiroteor/?num_registro=201000501648\&dt_publicacao $=01 / 02 / 2011>$. Acesso em: 15 fev. 2018.

BRASIL. Superior Tribunal de Justiça. Conflito de Competência no 119.218/DF. Relatora: Ministra Nancy Andrighi. Órgão Julgador: Segunda Turma. Julgamento em 25 abril 2012. Disponível em: $<$ https://ww2.stj.jus.br/processo/revista/inteiroteor/?num_registro $=201102404603 \&$ dt_publicacao $=02 / 05 / 2012>$. Acesso em: 15 fev. 2018.

BRASIL. Superior Tribunal de Justiça. Conflito de Competência n ${ }^{\circ}$ 134.471/PB. Relator: Ministro Raul Araújo. Órgão Julgador: Segunda Seção. Julgamento em 27 maio 2015. Disponível em: $<$ https://ww2.stj.jus.br/processo/revista/inteiroteor/? num_registro $=201401472171 \&$ dt_publicacao $=03 / 08 / 2015>$. Acesso em: 15 fev. 2018.

BRASIL. Superior Tribunal de Justiça. Habeas Corpus n² 294.729/SP. Relator: Ministro Sidnei Beneti. Órgão Julgador: Terceira Turma. Julgamento em 07 ago. 2014. Disponível em: <https://ww2.stj.jus.br/processo/revista/inteiroteor/?nnum_registro $=201401146249 \& d t \_p u b l i c a-$ cao $=29 / 08 / 2014>$. Acesso em: 15 fev. 2018.

BRASIL. Superior Tribunal de Justiça. Habeas Corpus n 404.545/CE. Relator: Ministro Ricardo Villas Bôas Cueva. Órgão Julgador: Terceira Turma. Julgamento em 28 fev. 2017. Disponível em: <https://ww2.stj.jus.br/processo/revista/inteiroteor/? num_registro=201701466748\&dt_publicacao $=29 / 08 / 2017>$. Acesso em: 15 fev. 2018. 
BRASIL. Superior Tribunal de Justiça. Medida Cautelar n 16.357/DF. Relatora: Ministra Nancy Andrighi. Órgão Julgador: Terceira Turma. Julgamento em 02 fev. 2010. Disponível em: < https://ww2.stj.jus.br/processo/revista/inteiroteor/?num_registro $=200902387870 \& d t$ publicacao $=16 / 03 / 2010>$. Acesso em: 15 fev. 2018.

BRASIL. Superior Tribunal de Justiça. Recurso Especial n 1.058.689/RJ. Relatora: Ministra Nancy Andrighi. Órgão Julgador: Terceira Turma. Julgamento em 12 maio 2009. Disponível em: < https://ww2.stj.jus.br/processo/revista/inteiroteor/?num_registro $=200801079883 \&$ dt_publicacao $=25 / 05 / 2009$ > . Acesso em: 15 fev. 2018.

BRASIL. Superior Tribunal de Justiça. Recurso Especial n 1.106.637/SP. Relatora: Ministra Nancy Andrighi. Órgão Julgador: Terceira Turma. Julgamento em 01 jun. 2010. Disponível em: <https://ww2.stj.jus.br/processo/revista/inteiroteor/?num_registro=200802608928\&dt_publicacao $=01 / 07 / 2010>$. Acesso em: 15 fev. 2018.

BRASIL. Superior Tribunal de Justiça. Recurso Especial n 1.199.940/RJ. Relatora: Ministra Nancy Andrighi. Órgão Julgador: Terceira Turma. Julgamento em 01 março 2011. Disponível em: <https://ww2.stj.jus.br/processo/revista/inteiroteor/?num_registro $=201001179745 \& d t$ publicacao $=04 / 03 / 2011>$. Acesso em: 15 fev. 2018.

BRASIL. Superior Tribunal de Justiça. Recurso Especial n 1.207.185/MG. Relator: Ministro Luis Felipe Salomão. Órgão Julgador: Quarta Turma. Julgamento em 11 out. 2011. Disponível em: $<$ https://ww2.stj.jus.br/processo/revista/inteiroteor/?num_registro=201001491100\&dt_publicacao $=22 / 11 / 2011>$. Acesso em: 15 fev. 2018.

BRASIL. Superior Tribunal de Justiça. Recurso Especial n 1.215.551/RJ. Relatora: Ministra Nancy Andrighi. Órgão Julgador: Terceira Turma. Julgamento em 17 março 2011. Disponível em: <https://ww2.stj.jus.br/processo/revista/inteiroteor/?.num_registro $=201001899085 \& d t$ publicacao $=30 / 10 / 2012>$. Acesso em: 15 fev. 2018.

BRASIL. Superior Tribunal de Justiça. Recurso Especial n 1.293.800/MG. Relator: Ministro Humberto Martins. Órgão Julgador: Segunda Turma. Julgamento em 28 maio 2013. Disponível em: $<$ https://ww2.stj.jus.br/processo/revista/inteiroteor/? num_registro=201102678672\&dt_publicacao $=05 / 06 / 2013>$. Acesso em: 15 fev. 2018.

BRASIL. Superior Tribunal de Justiça. Recurso Especial n 1.347.228/SC. Relator: Ministro Sidnei Beneti. Órgão Julgador: Terceira Turma. Julgamento em 06 nov. 2012. Disponível em: <https://ww2.stj.jus.br/processo/revista/inteiroteor/?num_registro=201200965571\&dt_publicacao $=20 / 11 / 2012>$. Acesso em: 15 fev. 2018.

BRASIL. Superior Tribunal de Justiça. Recurso Especial n 1.449.560/RJ. Relator: Ministro Marco Buzzi. Órgão Julgador: Quarta Turma. Julgamento em 19 ago. 2014. Disponível em: <https://ww2.stj.jus.br/processo/revista/inteiroteor/?num_registro=201400810413\&dt_publicacao $=14 / 10 / 2014>$. Acesso em: 15 fev. 2018.

BRASIL. Superior Tribunal de Justiça. Recurso Especial n 1.533.206/MG. Relator: Ministro Luis Felipe Salomão. Órgão Julgador: Quarta Turma. Julgamento em 17 nov. 2015. Disponível em: <https://ww2.stj.jus.br/processo/revista/inteiroteor/? num_registro=201403456537\&dt_publicacao $=01 / 02 / 2016>$. Acesso em: 15 fev. 2018. 
BRASIL. Superior Tribunal de Justiça. Recurso Especial n 1.567.812/SC. Relator: Ministro Raul Araújo. Órgão Julgador: Quarta Turma. Julgamento em 25 dez. 2016. Disponível em: < https://ww2.stj.jus.br/processo/revista/inteiroteor/?num_registro=201500354377\&dt_publicacao $=05 / 12 / 2016>$. Acesso em: 15 fev. 2018.

BRASIL. Superior Tribunal de Justiça. Recurso Especial n 1.613.641/MG. Relator: Ministro Ricardo Villas Bôas Cueva. Órgão Julgador: Terceira Turma. Julgamento em 23 maio 2017. Disponível em: <https://ww2.stj.jus.br/processo/revista/inteiroteor/?num_registro=201402912140\&dt_publicacao =29/05/2017> . Acesso em: 15 fev. 2018.

BRASIL. Superior Tribunal de Justiça. Recurso Especial n 964.836/BA. Relatora: Ministra Nancy Andrighi. Órgão Julgador: Terceira Turma. Julgamento em 02 abril 2009. Disponível em: <https://ww2.stj.jus.br/processo/revista/inteiroteor/?num_registro=200701510581\&dt_publicacao $=04 / 08 / 2009>$. Acesso em: 15 fev. 2018.

Data da submissão: 01 de maio de 2018 Aceito em: 12 de junho de 2018 
